\title{
面向工业废水处理的催化电极及燃料电池耦合体系
}

孙嘉琦 $^{1}$, 柳丽芬 ${ }^{1,2^{*}}$, 杨风林 ${ }^{1}$

1. 大连理工大学环境学院, 工业生态与环境工程教育部重点实验室, 大连 116024;

2. 大连理工大学海洋科学与技术学院, 工业生态与环境工程教育部重点实验室, 盘锦 12244

* 联系人, E-mail: lifenliu@dlut.edu.cn

2020-06-22 收稿, 2020-08-03 修回, 2020-09-02 接受, 2020-09-04 网络版发表

国家自然科学基金(21677025)资助

摘要随着我国工业化水平的提高, 工业废水的高效节能处理成为废水资源化与能源化进程中的重点和难点. 工 业废水中常含有难降解或有毒的有机污染物, 水质复杂、可生化性差, 采用传统废水处理技术(生物法、物化法等) 难以实现高效处理和达标排放, 残留毒物排入水体带来环境生态风险。电化学技术借助电场作用产生强氧化性物 质, 氧化去除难降解有机污染物, 但去除效率较低、能耗及运行成本较高, 限制了其在实际废水处理中的应用. 高 活性催化电极在结构、形貌、组成的优化进展, 为构建以难降解污染物为燃料的新型燃料电池及废水处理体系提 供了新的可能. 本文围绕催化电极及燃料电池废水处理体系, 综述了新型电极材料的制备、优化, 探讨了基底、活 性成分及其负载方式对催化电极和体系性能的影响; 归纳了基于光催化燃料电池和微生物燃料电池的污染物催化 降解及实际或模拟废水处理体系的研究进展, 并对该类耦合体系的规模化应用作了展望。新型催化电极的开发和 耦合燃料电池体系的优化设计, 有望推动该技术在高效、节能实际(工业)废水处理中的应用.

关键词催化电极, 电化学处理技术, 光催化燃料电池, 微生物燃料电池, 工业废水处理

水资源短缺成为 21 世纪人类面临的巨大挑战之一， 用水量的增加和水污染加剧了这一现状. 据统计, 2015 年全国废水排放总量达735.3亿吨，其中工业废水占 $27.1 \%(199.5 \text { 亿吨 })^{[1]}$. 与城镇生活污水不同，工业废水 成分复杂、可生化性差 ${ }^{[2]}$, 常含有染料(印染废水)、重 金属(冶炼、化工、电子等行业废水)、氭化物和多环 芳烃等有毒物质(焦化废水) $)^{[3]}$ 或抗生素等药物成分 (制 药废水)等. 这些有毒或难降解的污染物在传统生物或 物化废水处理系统中难以被高效降解, 通常需要深度 处理. 然而, 以超滤(UF)、反渗透(RO)等为代表的膜分 离技术，尽管可以通过物理截留过程实现污染物的分 离, 得到较优的出水水质, 但却无法实现污染物的降 解, 其自身的膜污染问题也增加了运行成本, 因此多用
于低浓度废水的深度处理与回用 ${ }^{[4,5]}$. 其他高级氧化技 术, 如湿式氧化法, 则需要高温、高压, 仅适用于小规 模的难降解废水处理; Fenton氧化法则需要投加 $\mathrm{Fe}^{2+}$ 和 $\mathrm{H}_{2} \mathrm{O}_{2}$, 增加了试剂消耗, 同时也易产生二次污染(如含 铁污泥), 在规模化的废水处理中并不是首选 ${ }^{[6]}$. 因此, 需要针对性地开发更加高效、环保、节能的新型废水 处理技术.

电化学技术, 包括电化学氧化、电化学还原、电 解、电絮凝等 ${ }^{[7]}$, 具有避免二次污染、设备简单、便 于调控等优点, 被称为“环境友好型”技术 ${ }^{[8]}$. 利用电场 驱动电极表面直接或间接的氧化还原反应, 可实现难 降解污染物的深度去除, 在水质复杂、难生化的工业 废水处理领域应用前景广阔. 然而, 采用传统电极的电

引用格式: 孙嘉琦, 柳丽芬, 杨风林. 面向工业废水处理的催化电极及燃料电池耦合体系. 科学通报, 2021, 66: 2378-2392

Sun J Q, Liu L F, Yang F L. Progress on catalytic electrodes and fuel cell systems for industrial wastewater treatment (in Chinese). Chin Sci Bull, 2021, 66 2378-2392, doi: 10.1360/TB-2020-0747 
化学技术通常需要较强的外加电场来驱动电极反应, 在处理污染程度较高的实际废水过程中依然存在能耗 高、易发生副反应等不足. 因此, 需要对其进行改良. 将光/电催化技术引人电化学系统, 构建电催化 (electrocatalytic, EC)或光电催化(photo-electrocatalytic, PEC)耦 合体系, 是电化学技术的优化策略之一. 催化剂的使用 降低了电极/污染物反应的活化能, 能够在较低电压下 驱动化学反应, 提高污染物去除速率并减少能耗. 新 型、高活性催化电极的开发为电化学耦合体系在工业 废水处理中的应用提供了更多的可能性.

尽管催化电极引入的光/电催化过程能够提高难降 解污染物的去除效率, 但外加电场带来的能源消耗及 运行成本依然是EC或PEC耦合工艺放大化应用中的主 要限制因素. 例如, Ding等人 ${ }^{[9]}$ 采用BDD或DSA催化阳 极、石墨毡或钛网阴极和铁网双电极, 构建了耦合电 絮凝的 $\mathrm{EC}$ 体系. 该工艺可在 $1.5 \mathrm{Ah} \mathrm{L}^{-1}$ 的负荷下去除垃 圾渗滤液中 $50 \%$ 60\%的有机物(chemical oxygen demand, $\mathrm{COD})$ 和 $100 \%$ 的氨氮 $\left(\mathrm{NH}_{4}{ }^{+}-\mathrm{N}\right)$, 能耗为 $15 \mathrm{kWh} \mathrm{m}^{-3}$; 但经过经济和能耗的综合考量, 该工艺无 法满足更高标准(COD去除率 $>70 \%$ ) 的废水处理需求. Baldisserri等人 ${ }^{[10]}$ 在外加电、外加光的PEC体系中实现 了对染料废水的高效处理, 但外加电场 $(5 \mathrm{~V}, 3.2 \mathrm{~A})$ 、外 加试剂 $\left(\mathrm{Na}_{2} \mathrm{CO}_{3} / \mathrm{NaCl}\right)$ 、贵金属电极材料 $(\mathrm{Pd})$ 和紫外光 的使用均使得该工艺具有较高的运行成本. 因此, 通过 电极和体系的优化提高能源利用效率是光/电催化耦合 技术的重要发展方向之一，有望推动该技术在实际中 的应用.

与需要外加电场的电化学技术相比, 能够转化污 染物产电的燃料电池则是一类更加绿色、节能、可持 续的新型电化学废水处理技术，符合废水资源化与能 源化的发展目标. 以光催化燃料电池(photocatalytic fuel cell, PFC)和微生物燃料电池 (microbial fuel cell, MFC) 为基础构建的新型自偏压的电化学体系, 能够以废水 中的污染物作为“燃料”, 在有光或无光的条件下将化 学能转化为电能, 同步实现污染物降解和能源回收、 催化和产电等多技术耦合的特点使其在处理复杂水质 废水时具有独特优势. 在这类自产电的电化学耦合体 系中, 电极的催化活性和稳定性直接决定着污染物的 降解性能和能源转化效率 ${ }^{[11]}$. 新型、高效催化电极的 开发, 及其在燃料电池耦合体系中的创新性应用, 为难 降解工业废水的能源化处理提供了新思路.

近来, 随着研究的不断深人, 新型燃料电池泊合水
处理体系已在工业废水处理及难降解污染物去除方面 展示出巨大的应用潜力, 但在污染物去除速率、能源 回收效率和规模化应用等方面还存在进一步优化的空 间, 值得深人探索. 本文围绕高活性催化电极及燃料电 池型电化学废水处理技术，对国内外学者在电极制备 和优化方面的研究进行回顾和总结, 并对基于光催化 燃料电池和微生物燃料电池的新型电化学耦合体系在 处理典型工业污染物或实际工业废水方面的研究作了 梳理和展望, 推动该类绿色、可持续技术的工业化 应用.

\section{1 高活性催化电极的制备}

催化电极的性能主要取决于催化活性材料, 其组 分、结构的优化设计直接影响电极的光/电催性能. 在 电催化体系中，催化组分在电场的作用下改变电极反 应速率, 因此需要电极具备良好的导电性和电化学(催 化)活性. 而在光-电催化体系中, 则需要发挥光催化与 电催化之间的协同作用, 要求电极上的催化活性组分 能够在光激发下产生电子-空穴对的同时，利用电化学 作用辅助电子的迁移, 从而实现高效的光电催化. 这种 特殊的多相催化不仅需要电极具备导电性和电化学活 性等基本特征，还要兼顾催化组分在电极表面对光的 响应能力, 因此在催化活性材料的选择、制备和负载 方式上都有更高的要求.

贵金属 $(\mathrm{Ag} 、 \mathrm{Pt} 、 \mathrm{Pd}$ 等)虽然具有优良的导电性和 化学稳定性, 但成本高且催化效率有限, 并不是新型电 化学体系的首选 ${ }^{[11]}$. 自Fujishima和Honda ${ }^{[12]}$ 发现二氧化 钛 $\left(\mathrm{TiO}_{2}\right)$ 具有光催化及电催化活性以来, 更为廉价、高 效的半导体金属(复合)氧化物、氢氧化物或硫化物, 如 $\mathrm{Ti}_{4} \mathrm{O}_{7}{ }^{[13]} 、 \mathrm{MnO}_{2}{ }^{[14]} 、 \mathrm{ZnO}^{[15]} 、 \mathrm{CdS}^{[16]} 、 \mathrm{Co}(\mathrm{OH})_{2}{ }^{[17]}$ 、 $\mathrm{FeOOH}^{[18]} 、 \mathrm{MnFe}_{2} \mathrm{O}_{4}{ }^{[19]} 、 \mathrm{BiVO}_{4}{ }^{[20]}$ 等, 已在光催化或 电催化领域得到了广泛应用. 碳纳米管、石墨烯、石 墨相氮碳化合物等高活性碳基催化材料 ${ }^{[21 ~ 24]}$, 以及沸

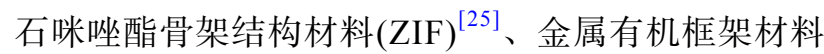
$(\mathrm{MOF})^{[26,27]}$ 及过渡金属碳/氮化物(MXene) $)^{[28]}$ 等新材料 的出现, 为光/电催化剂的优化和复合改性提供了更多 可能. 随着研究的不断深人, 各类异质结半导体催化 剂 ${ }^{[29,30]}$ 、单原子催化剂 ${ }^{[31]}$ 等高活性催化材料可呈现出 纳米花、纳米线、纳米棒或核壳状等多种结构 ${ }^{[32 ~ 34]}$, 在光/电催化降解和能源回收等方面潜力巨大. 然而, 大 多数(超)高活性催化材料均呈纳米粉末状, 分散在水体 中难以回收和重复利用, 不仅增大了运行成本, 也容易 
造成二次污染，甚至会对工厂化的生物处理系统产生 毒害作用 ${ }^{[35]}$ ，严重限制了高效光/电催化技术的工业化 应用.

将催化剂负载于导电基底，制备高活性催化电极, 不仅可以克服粉末状催化剂在废水处理应用中的不 足、扩大光/电催化技术的应用领域, 还可以为电化学 体系引人多种协同作用机制、提高体系的综合性能. 从催化剂到催化电极, 不仅需要优化材料的催化性能, 还要综合考虑基底和负载方式对电极光/电催化活性和 稳定性的影响. 理想的催化电极应具备如下特征：(1) 制备方法简单、原料易得、成本低; (2) 具有良好的机 械性能和物理、化学稳定性, 无毒害作用; (3) 具有(超) 高的光/电催化活性, 可高效去除目标污染物, 矿化率 高、副产物少; (4) 催化组分负载牢固, 电极催化性能 稳定, 可重复使用. 如何通过材料制备和负载方式的优 化, 提高催化电极的综合性能和功能, 是现阶段研究中 的重点和难点. 根据电极的形貌结构, 可将高活性催化 电极分为自支撑催化电极、膜状催化电极和其他形态 催化电极等.

\section{1 自支撑催化电极}

自支撑催化电极是指催化活性材料自身具有一定 的机械强度和几何形状, 可直接作为电极使用, 无需载 体提供辅助支撑. 这类电极的优势在于催化组分与基 底(作为催化组分的一部分)密切接触, 传质阻力小, 更 容易发挥出材料的全部催化活性. 尤其对于光电催化 电极, 其活性组分可以不受其他物质遮挡, 直接接收光 照, 这种制备或改性方式优势显著. 但在材料制备过程 中需要兼顾其催化活性、导电性和机械性能，与粉末
状催化剂的制备相比具有一定的技术难度. 随着催化 活性材料的不断优化, 新型自支撑电极在组分、结 构、形貌和功能上均有一定的创新，根据基底或原材 料的种类, 可将其分为金属基、碳基或其他.

\subsection{1 金属基自支撑催化电极}

以具有支撑结构的廉价金属, 如不锈钢 ${ }^{[36]}$ 、 钛 $^{[37]}$ 、铜 ${ }^{[38]}$ 、铇 ${ }^{[39]}$ 、钿 ${ }^{[40]}$ 等为基底或原材料, 通过水 热反应、电化学氧化、化学气相沉积等方法可制备高 活性二维或三维金属基自支撑催化电极，催化层组分 和微观形貌直接影响电极的性能. 例如, Xia等人 ${ }^{[41]}$ 以 铇片作为基底和原材料，首先采用阳极氧化法原位制 得具有纳米孔结构的 $\mathrm{WO}_{3} / \mathrm{W}$, 之后采用旋涂法负载多 层 $\mathrm{BiVO}_{4}$, 得到 $\mathrm{BiVO}_{4} / \mathrm{WO}_{3} / \mathrm{W}$ 光催化阳极, 催化层呈致 密薄膜状. $\mathrm{WO}_{3}$ 和 $\mathrm{BiVO}_{4}$ 形成的异质结使该电极能够很 好地响应可见光，获得比纯 $\mathrm{WO}_{3}$ 和 $\mathrm{BiVO}_{4}$ 电极高 $180 \%$ 和 $205 \%$ 倍的光电流, 且能够在PFC中降解多种染料、 抗生素和难降解有机污染物, 得到最高 $348.3 \mu \mathrm{W} \mathrm{cm}{ }^{-2}$ $\left(0.05 \mathrm{~mol} \mathrm{~L}^{-1}\right.$ 苯酚 $)$ 的产电.

与普通二维金属材料(金属片、金属网、金属丝 等)相比，三维多孔金属结构(泡沫)不仅具有良好的机 械强度和导电性, 还具有更大的比表面积, 可提供更多 的表面活性位点 ${ }^{[42]}$. 金属泡沫表面的催化活性层不仅 提高了光/电催化活性，还保护了金属基底，使其在电 化学体系的中具有更好的稳定性 ${ }^{[43]}$. Zhang等人 ${ }^{[44]}$ 在镍 泡沫 $(\mathrm{NiF}$ 或 $\mathrm{NF}$ )基底上垂直生长 $\mathrm{ZnO}$ 纳米棒阵列, 并沉 积纳米 $\mathrm{Ag}$ 颗粒, 制备了三维纳米复合光电催化电极 $\mathrm{Ag}$ $\mathrm{NPs} / \mathrm{ZnONAs} / \mathrm{NiF}$ (图1). 该电极具有超高的光电催化活 性，在紫外和可见光照射下均可产生 $\cdot \mathrm{OH}$ 和 $\cdot \mathrm{O}_{2}^{-}$, 高效 降解甲基橙(紫外， $60 \mathrm{~min}, 99 \%$ )和黄连素(紫外,

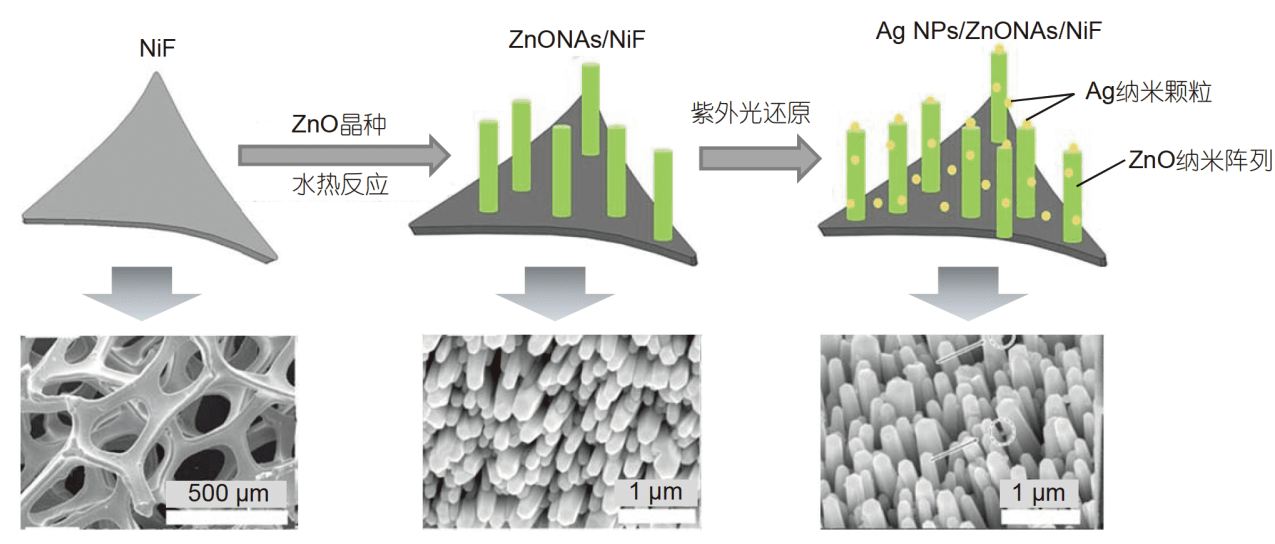

图 1 (网络版彩色)高活性三维自支撑光电催化电极 $\mathrm{Ag} \mathrm{NPs} / \mathrm{ZnONAs} / \mathrm{NiF}$ 的制备 ${ }^{[44]}$

Figure 1 (Color online) Schematic diagram of the preparation of highly-active 3D self-standing photo-electro-catalytic electrode of Ag NPs/ZnO $\mathrm{NAs} / \mathrm{NiF}^{[44]}$ 
$120 \mathrm{~min}, 97.9 \%$; 可见, $60 \mathrm{~min}, 98.9 \%$ ). Yang等人 ${ }^{[45]}$ 将新 型3D MOF材料用于镍泡沫催化改性, 通过三步法(电沉 积、立体组装与自增强催化裂解)制备了具有超高电解 水催化活性的Co@N-CNT/NF自支撑电极, 其独特的三 维分层管状结构和各组分之间的协同作用为电催化提 供了更多的反应活性位点, 加速了电子/电解质的扩散, 从而提高了电极的导电性、亲水性和结构稳定性.

金属基三维自支撑催化电极在储能 ${ }^{[42]}$ 、传感 ${ }^{[43]}$ 和 压电 ${ }^{[46]}$ 等领域已有应用, 但在废水污染控制体系中的 应用较少，其主要限制因素在于金属基底在电化学、 水溶液环境中的稳定性较差. 如何在催化改性的同时 增强金属基底的稳定性，以及如何扩大电极改性的面 积, 是该类催化电极走向废水处理实际应用中需要攻 克的关键性技术问题.

\subsection{2 碳基自支撑催化电极}

廉价、易得的碳基材料, 包括如碳纤维、碳布、 碳纸等, 具有优良的导电性、化学惰性、电化学稳定 性和一定的机械强度, 碳毡和碳泡沫等多孔材料还具 有巨大的比表面积, 在催化改性方面具有金属材料无 法替代的独特优势. 新型、高活性二维或三维结构的 碳基自支撑催化电极的开发有望在提升耦合体系性能 的同时进一步降低材料成本. 例如, Jia等人 ${ }^{[47]}$ 以碳布 (CC)为基底, 通过两步电沉积法制得的二维碳基自支 撑催化电极 $\mathrm{Co} @ \mathrm{NC} / \mathrm{CC}$ 在电化学体系中具有超高的苯 酚催化降解活性(1.340 $\left.\mathrm{min}^{-1}\right)$ 以及析氢、析氧反应活 性. Guo等人 ${ }^{[48]}$ 则创新性地制备了石墨泡沫基底, 通过 水热法负载氮掺杂的石墨烯量子点 $(\sim 5 \mathrm{~nm})$, 得到氮掺 杂石墨烯量子点修饰石墨泡沫(N-GQDs/GF)自支撑电 极; 该电极不仅导电性好、具有较低的析氢过电位 (-72 mV vs. RHE(可逆氢电极), $10 \mathrm{~mA} \mathrm{~cm}{ }^{-2}$ ), 还可活 化过硫酸盐快速降解苯酚 (50 min, 100\%). 以非金属代 替金属, 降低了催化电极和废水处理的成本.

此外, 利用碳基材料的独特优势, 新型、高活性碳 基自支撑催化电极有望原位耦合多种作用机制, 提高 电化学技术的能源利用和回收效率. 例如, Tang 等人 ${ }^{[49]}$ 采用一步水热法, 制备了 $\mathrm{FeMoO}_{4}-\mathrm{GO} / \mathrm{CFC}$ 自支撑催化 阴极, 能够在光电协同作用下高效降解黄连素 $(30 \mathrm{~min}$, $>90 \%$ ), 并以 $3.1 \mathrm{mmol} \mathrm{cm} \mathrm{min}^{-1}$ 的速率回收氢能源, 实现了制药废水的能源化处理. Sun等人 ${ }^{[50]}$ 采用一步水 热法在碳毡 $(\mathrm{ACF})$ 上垂直生长三氧化铇/聚吡咯 $\left(\mathrm{WO}_{3} /\right.$ PPy)纳米片, 经过复合比例的优化, 得到具有较大比表 面积 $\left(788.27 \mathrm{~m}^{2} \mathrm{~g}^{-1}\right)$ 、优良电容性 $\left(2.58 \mathrm{~F} \mathrm{~cm}^{-2}\right)$ 和电催
化活性的 $\mathrm{WO}_{3} / \mathrm{PPy}-1 / \mathrm{ACF}$; 作为阴极, 该电极可在低电 压(1.0 V)下同时去除重金属离子 $\left(\mathrm{Cu}^{2+}, 97.8 \%\right)$ 和有机 酸(CA，80.1\%), 利用电吸附-电沉积-电催化的协同作 用, 提高复合污染物的去除效率, 降低能耗 $(8.12 \mathrm{~kW} \mathrm{~h}$ $\mathrm{kg}_{\mathrm{Cu}}{ }^{-1}$ 和 $2.54 \mathrm{~kW} \mathrm{~h} \mathrm{~kg}{ }_{\mathrm{COD}}{ }^{-1}$ ), 为新型电化学体系的构建 及重金属/有机酸复合工业废水的高效、低成本处理提 供了新思路.

碳基材料化学性质稳定, 催化改性方法丰富, 但催 化材料负载的牢固程度和电极的机械强度是该类自支 撑催化电极在制备和改性过程中需要重点考量的因素. 当电极面积进一步扩大, 碳基自支撑催化电极能否在 长期、连续的实际废水处理体系中保持机械性能和催 化性能的稳定, 还有待进一步的考察.

\subsection{3 其他自支撑催化电极}

除了常规的金属和碳材料, $\mathrm{Li}$ 等人 ${ }^{[51]}$ 采用不导电 的棉织物作为原材料, 通过动态模板 $\left(\mathrm{KOH} 、 \mathrm{SiO}_{2}\right.$ 和 $\mathrm{Al}_{2}$ $\mathrm{O}_{3}$ ) 炦烧的方法成功制备了分层多孔中空碳纤维织物 自支撑电极. 此外, 以导电聚合物作为原料, 也可催化 改性得到自支撑电极 ${ }^{[52]}$. 然而, 对于实际应用来说, 聚 合物自支撑电极的柔性和机械强度还需进一步强化.

打印电极是近年来发展迅速的新型自支撑催化电 极. 采用3D打印或丝网印刷 ${ }^{[53]}$ 技术, 可以定制电极的成 分和形貌, 精确调控催化活性、比表面积、传质性能 等一系列参数, 有望替代目前常见的金属或碳基催化 电极 ${ }^{[54]}$. 熔丝模型法(FDM) 是3D打印中最常采用的方 法, 其中以聚乳酸(PLA)和石墨烯或其他导电碳化合物 的混合物为基础的导电丝已被应用于新型电极的制备 和电池、传感器等电化学体系 ${ }^{[55]}$. 然而, 印刷制备的电 极在电荷转移方面效率仍然较低, 需要一些后续处理 以进一步提高打印电极的电化学性能或催化性能 ${ }^{[56]}$. Iffelsberger等人 ${ }^{[57]}$ 通过常温电化学沉积法对3D打印电 极进行改性, 得到负载 $\mathrm{MoS}_{x}$ 的催化电极用于催化产氢. 类似的催化改性还可通过喷涂 ${ }^{[87}$ 等方式实现. 虽然打 印技术在电极制备(电化学性能优化、催化改性、形 貌结构调控等)和污染控制应用(污染物降解、能源回 收)等方面的研究还处于起步阶段, 但现有成果已经展 现出这类定制催化电极的巨大改性空间和应用潜力.

\section{2 膜状催化电极}

催化剂通过黏合剂或自组装的方式负载于导电基 底, 形成薄膜状催化层, 可得到薄膜催化电极. 其中, 采 用黏合剂将催化剂涂覆 (浸渍涂覆 ${ }^{[59]}$ 、旋转涂覆 ${ }^{[60]}$ 等) 
负载于基底表面, 是最简便的制备方式之一, 可以扩大 化生产, 在实际应用中优势显著, 但需要综合考虑包覆 在材料表面的黏合剂对催化活性材料性能(尤其是光 电催化性能)的影响、催化剂附着的牢固程度以及电 极的导电性、稳定性等综合性能. 以导电玻璃(ITO和 FTO)为基底, 将催化剂粉末与Nafion溶液混合后负载, 是传统的电极制备方法, 但成本较高, 难以实现规模化 应用 ${ }^{[61 ~ 63]}$. Nahyoon等人 ${ }^{[64]}$ 使用廉价的硅溶胶将催化剂 多次刷涂于碳纤维布或不锈钢网上, 简便地制备了高 活性Fe/GTiP催化阳极和ZnIn ${ }_{2} \mathrm{~S}_{4}$ 催化阴极用于构建高 效PFC体系; 透明的硅溶胶不影响催化剂对可见光的吸 收, 电极能够充分发挥光电催化活性, 在降解罗丹明B $(\mathrm{RhB})$ 的同时产生 $0.4 \mathrm{~V}$ 电池电压, 实现了染料废水的能 源化处理和应用.

采用聚偏氟乙烯(PVDF)、聚砜(PSF)、聚乙烯醇 $(\mathrm{PVA}) 、$ 聚丙烯酸 $(\mathrm{PAA})$ 等成膜聚合物作为黏合剂, 还 可以通过优化铸膜液组分提高催化层的膜分离系性能, 得到催化电极膜. 这类新型电极是光/电催化技术与膜 分离技术的进一步耦合, 不仅制备方法简单、原料廉 价易得, 还可以实现污染物的原位催化降解和选择性 分离, 强化电催化耦合体系中污染物的去除, 并同时减 缓膜污染 ${ }^{[65]}$. 尽管这类不导电、非透明的成膜聚合物 可能会影响电极的导电性或减弱电极表面催化剂对光 的吸收能力, 但通过铸膜液中各组分的优化, 仍可使电 极膜具备良好的电催化或光电催化活性. 这类催化电 极膜利用光/电催化与膜分离的协同作用极大地扩展了 催化电极在(微生物)电化学耦合体系中的应用领域, 目 前已成为新型、高活性催化电极的研究热点之一.

$\mathrm{Yu}$ 等人 ${ }^{[66]}$ 采用刷涂的方式在涤纶滤布上负载聚苯 胺(PANI)或碳泡沫-Fe-Co催化剂, 得到平板式PVDF催 化电极膜(图2(a)). 该膜具有良好的氧还原(ORR)活性, 作为阴极利用滤布的过滤性能和催化层的催化活性在 MBR-MFC体系中强化污染物的降解. $\mathrm{Li}^{\text {等人 }}{ }^{[67]}$ 是对 PVDF膜分离层进行原位催化改性(Pd-RGO-CoFe $\left.{ }_{2} \mathrm{O}_{4}\right)$, 采用相转化法在碳纤维布基底上刮制成膜(图2(b)). 研 究表明, 较薄的催化膜层 $(300 \mu \mathrm{m})$ 能够使催化电极膜具 有更高的电导率、ORR活性, 以及更优的膜孔结构, 使 电极膜在MBR-MFC体系中同时具有优良的催化活 性、膜分离性能和抗污染性能. 通过改变制膜材料和 方法可以制备具有特殊形貌的催化电极膜. Allioux等 人 $^{[68]}$ 通过干湿纺丝及热烧结组合工艺制备了含有金属 粉末 $(\mathrm{Ni}$ 和 $\mathrm{NiCu})$ 的改性中空纤维膜. 该膜在有机污染物
(水杨酸)电催化氧化方面具有比纯铂丝高9 20倍的降 解速率, 且具有优良的稳定性, 可重复使用. 高效催化 膜及催化电极膜开发为电化学耦合废水处理技术的优 化提供了新的思路.

采用自组装的方式在基底表面原位形成致密的薄 膜状催化层, 可得到具有多种微观形貌特征的薄膜催 化电极, 常用制备方法包括水热法 ${ }^{[69]}$ 、溶胶-凝胶 法 $^{[70]}$ 、电化学法 ${ }^{[71]}$ 、电沉积法 ${ }^{[69,72]}$ 、化学气相沉积 法 $^{[73]}$ 、气相聚合法 ${ }^{[74]}$ 、磁控溅射法 ${ }^{[75]}$ 、电喷雾 ${ }^{[76]}$ 等, 多元催化电极可组合多种方法逐步制备 ${ }^{[77,78]}$. 例如, Yu 等人 ${ }^{[79]}$ 利用 $\mathrm{TiO}_{2}$ 溶胶的特性, 在碳纤维布表面浸渍涂 覆 $\mathrm{TiO}_{2} / \mathrm{g}-\mathrm{C}_{3} \mathrm{~N}_{4}$ 催化层, 一步实现催化剂的复合与负载. 该催化电极在碱性介质中具有超高的光电催化氧化活 性, 能够在PFC体系中降解RhB并同时自偏压产电. 这 类电极对催化材料的制备方法有特殊要求, 如何改进 制备条件, 优化薄膜状催化电极的微观形貌, 进而提高 其催化活性和稳定性, 是新型、高效薄膜催化电极重 要的研究方向.

\section{3 颗粒催化电极}

颗粒催化电极作为一种新的电极形态, 突破了传统 二维电极的固有限制, 可作为流动床构建三维电化学体 系 ${ }^{[80]}$. 颗粒态的催化电极通过静电感应极化, 形成众多 的微电极, 作为二维电极的补充, 增大了电极的比表面 积和催化活性位点, 缩短了反应物的迁移距离, 可有效 提高体系的电流效率和污染物去除能力 ${ }^{[81]}$. 由于颗粒态 催化电极不需要大面积的机械支撑, 其基底或原材料的 选择范围较大. Hou等人 ${ }^{[82]}$ 采用一步法(碳化+铁负载)制 备的污泥活性炭-氧化铁 $\left(\mathrm{SAC}-\mathrm{Fe}\right.$ ) 比纯 $\mathrm{Fe}_{3} \mathrm{O}_{4}$ 纳米颗粒 具有更大的吸附容量和污染物催化降解速率. $\mathrm{Ye}$ 等 人 ${ }^{[83]}$ 采用活性炭 $(\mathrm{AC})$ 作为载体, 制备的 $\mathrm{Co} / \mathrm{AC}_{0.9} \mathrm{AB}_{0.1}$ 颗 粒电极能够实现硝酸盐的电催化还原. 此外, 钢渣 ${ }^{[84]}$ 、 碳气凝胶 ${ }^{[85}$ 等均可作为颗粒催化电极的载体. 然而目 前这类电极多用于外加电的催化耦合体系(如三维电 芬顿体系)中, 高效、低成本颗粒态光/电催化电极的开 发, 及其在自产电催化耦合体系中的创新性应用, 是这 类电极未来的研究和优化方向.

\section{2 高活性催化电极在燃料电池耦合废水处理 体系中的应用}

新型、高活性光/电催化电极的开发为新型电化学 耦合体系的构建提供了多种可能性, 其中, 以PFC和 
(a)

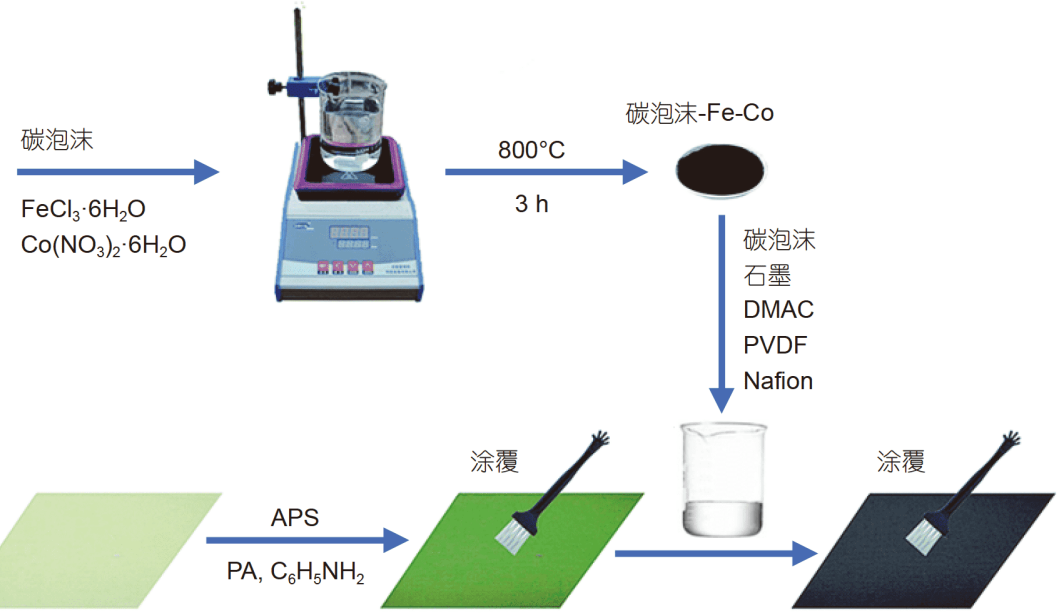

(b)

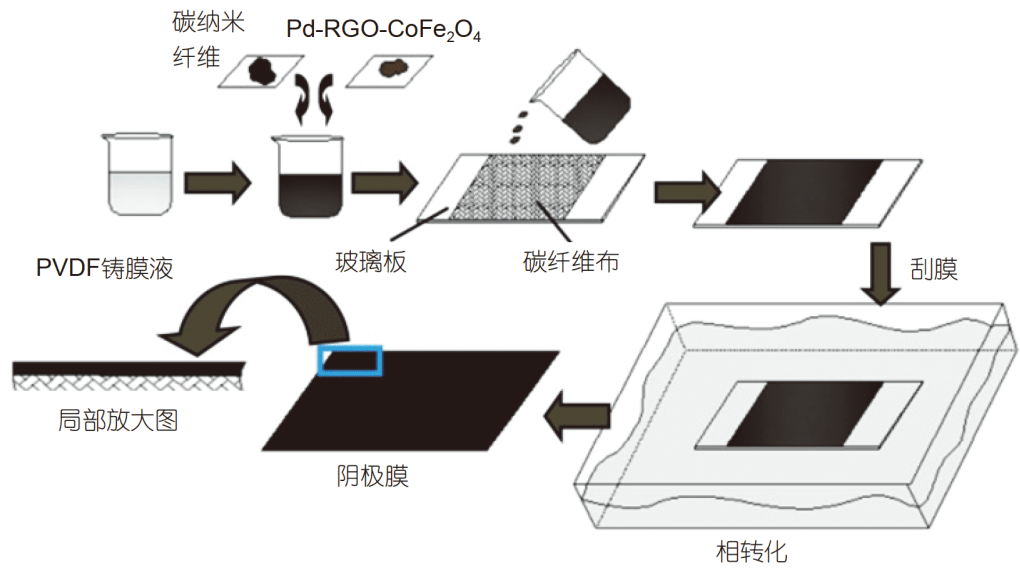

图 2 (网络版彩色)泡沫炭- $\mathrm{Fe}-\mathrm{Co}$ 催化剂及膜电极 ${ }^{[66]}(\mathrm{a})$ 以及Pd-RGO-CoFe $\mathrm{O}_{4}$ 催化阴极膜 ${ }^{[67]}$ (b)的制备流程

Figure 2 (Color online) Preparation process of carbon foam-Fe-Co catalyst and membrane electrode ${ }^{[66]}$ (a) and $\mathrm{Pd}-\mathrm{RGO}_{-} \mathrm{CoFe} \mathrm{O}_{4}$ cathode membrane ${ }^{[67]}(\mathrm{b})$

$\mathrm{MFC}$ 为代表的电池型废水处理体系是催化电极在自产 电体系中的两个重要应用方向. 燃料电池耦合体系在 难降解工业废水资源化与能源化应用方面显示出了巨 大的潜力.

\section{1 光催化燃料电池}

光催化燃料电池利用阴极和阳极光催化剂之间费 米能级差驱动电子流动，电极之间半导体能带结构的 匹配程度直接决定了PFC对污染物的降解效率和产电 效率 ${ }^{[86]}$. 此外, 电解液和底物的组成、浓度、 $\mathrm{pH}$ 等也是 PFC 综合性能的主要影响因素 ${ }^{[87]}$. 相较于单一的光催化 (PC)或电催化(EC)体系, PFC能够有效提高电子-空穴 的产生及分离效率(外电路传导、电极反应或污染物降 解消耗), 促进光电协同作用下活性氧自由基(ROS)或 其他氧化/还原性物质的生成, 从而提高污染物的降解 速率，同时提升产电，其耦合作用机理如图3(a)所示 ${ }^{[88]}$ PFC中光、电催化技术的耦合不仅增强了体系对难降 解污染物的去除能力, 还实现了电能的回收.

如表S1所示, 采用高活性催化电极的PFC已被用于 染料、抗生素及其他多种典型工业污染物或实际工业 废水的处理, 通过电极和体系的优化, 产电(开路电压) 已可达到 $1 \mathrm{~V}$ 及以上. Rabé等人 ${ }^{[89]}$ 分别以 $\mathrm{g}-\mathrm{C}_{3} \mathrm{~N}_{4} / \mathrm{Fe}^{0}$ $(1 \%) / \mathrm{TiO}_{2}$ 和 $\mathrm{WO}_{3}$ 作为阳极和阴极催化材料, $\mathrm{PFC}$ 在可 见光照射下可降解 $98 \%$ 的 $\mathrm{RhB}(\mathrm{pH}$ 2)并产生 $0.95 \mathrm{~V}$ 的电 池电压, 在处理实际焦化废水 $(\mathrm{pH} 2)$ 时同样可以利用自 偏压 $(0.3 \mathrm{~V})$ 去除 $91 \%$ 的COD和 $89 \%$ 的TOC. Wang等

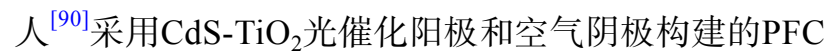
可在模拟太阳光照射下实现多种有机污染物(苯酚、 甲醇、乙酸、葡萄糖、双酚 $\mathrm{A}$ 等)的降解，最大功率密 度达708 $\mathrm{mW} \mathrm{cm}^{-2}$. Yu等人 ${ }^{[91]}$ 以碳纤维布为基底构建 
(a)

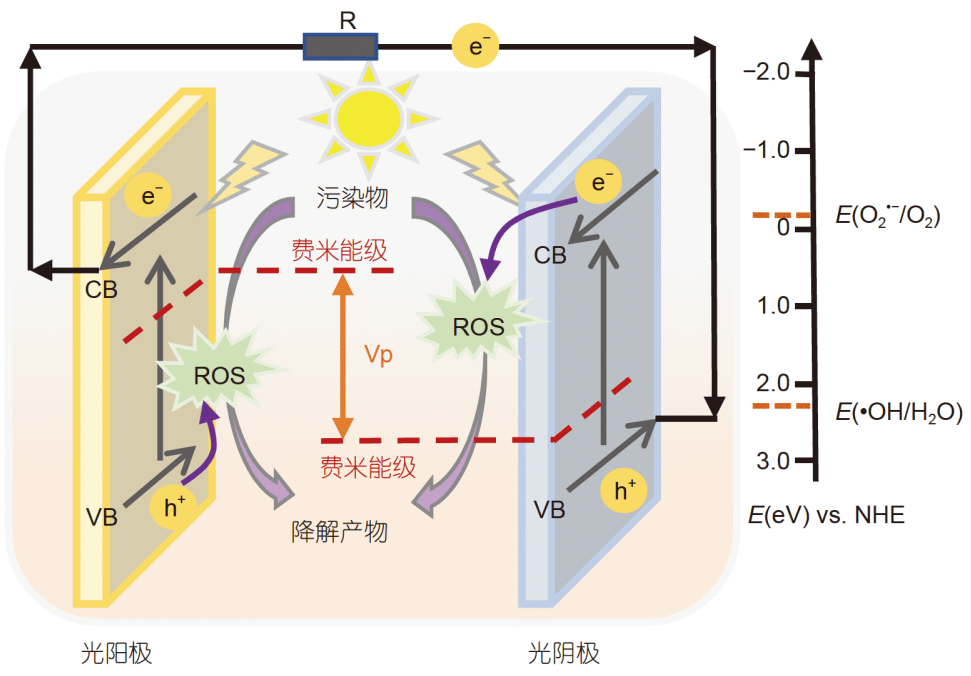

(b)

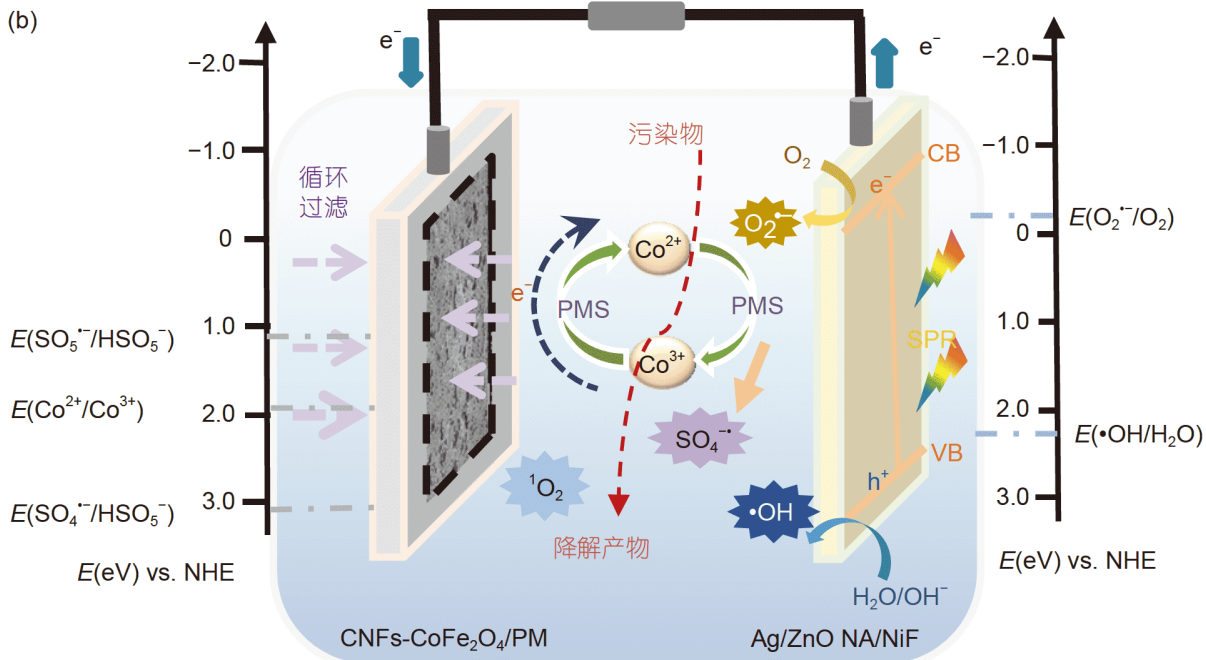

图 3 (网络版彩色)双光电极 $\mathrm{PFC}^{[88]}(\mathrm{a})$ 和PMS/PFC-MR耦合体系 ${ }^{[93]}$ (b) 原理示意图

Figure 3 (Color online) Schematic diagram of a dual-photoelectrode $\operatorname{PFC}^{[88]}$ (a) and PMS/PFC-MR integrated system ${ }^{[93]}$ (b)

了三元Z型复合p-ZnIn ${ }_{2} \mathrm{~S}_{4} / \mathrm{rGO} / \mathrm{n}-\mathrm{g}-\mathrm{C}_{3} \mathrm{~N}_{4}$ 催化阳极，与对 电极 $(\mathrm{Pt})$ 组成燃料电池体系, 在无光状态下即可自偏压 催化降解 $78 \%$ 的三氯生, 进一步减少了燃料电池体系光 源对电能的消耗; 此外, 外加可见光 $(2 \mathrm{~W})$ 或紫外光 $(20 \mathrm{~W})$ 后可将降解率提升至 $83 \%$ 和 $98.8 \%$ ，表明光电协 同作用有助于激发产生更多的活性自由基，增强体系 对污染物的降解能力.

由于半导体电极的固有局限性，自由基反应仅发 生在光阳极和阴极(或光阴极)表面. 通过加人少量辅助 催化剂(如过一硫酸盐(PMS)、过硫酸盐(PS)、 $\mathrm{Fe}^{2+}$ ) 将 硫酸根自由基、Fenton反应等高级氧化(advanced oxidation processes, AOPs)技术引入PFC体系可显著提高 $\mathrm{PFC}$ 溶液体系中的自由基反应效率, 提升污染物降解速
率及产电 ${ }^{[92]}$. Zhang等人 ${ }^{[93]}$ 将催化膜电极 $\left(\mathrm{CNFs}^{-\mathrm{CoFe}_{2}-}\right.$ $\mathrm{O}_{4} / \mathrm{PVDF}$ )用于PMS/PFC-MR耦合体系中, 实现了光催 化、电催化、PMS高级氧化和膜分离等多项技术的原 位耦合，作用机理如图3(b)所示. PMS的加人为体系提 供了硫酸根自由基，新的电子转移途径的构建将黄连 素的降解速率 $(1 \mathrm{~h})$ 和体系产电分别提高了 $65.9 \%$ 和 1.5 倍. 与之类似, PFC-PMS ${ }^{[94]} 、$ PFC-PS ${ }^{[95]} 、 \mathrm{PFC}-F e n-$

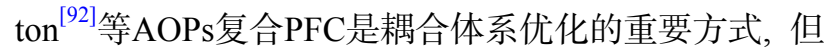
外加试剂的成本及其带来的副产物是这类耦合体系在 技术优化和实际应用中需要考量的重要因素.

\section{2 微生物燃料电池}

微生物燃料电池是以具有特殊产电功能的微生物 
(希瓦氏菌、地杆菌等)作为电子供体, 利用微生物同时 实现污染物降解及产电的新型厌氧废水处理技术, 是 生物处理技术与电化学处理技术的结合. 与上流式厌 氧污泥床(up-flow anaerobic sludge bed, UASB)、厌氧 膨胀颗粒污泥床(expanded granular sludge bed, EGSB) 或内循环式厌氧反应器(internal circulation, IC)等传统 戻氧生物处理工艺相比，其最大的优势在于兼顾污染 物降解和能源回收, 符合未来废水处理技术能源化的 发展的方向. 同时, 由于具备微生物和电化学耦合作用 机制, 在强化难降解污染物去除方面有很大的潜力. 然 而，目前该技术还未得到广泛的应用，其主要限制因素 在于生物体系电子传递速率决定的较低的能源回收效

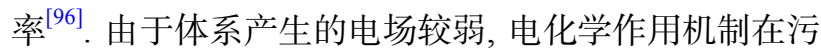
染物降解中也难以发挥作用. 因此, 强化污染物去除的 同时提高MFC的电子回收率/电流密度是该技术发展 的重点和难点，也是MFC体系走向实际应用需要克服 的技术难关.

除产电微生物外，电极是决定MFC综合性能的重 要组成部分. 优化电极(阴极或阳极)可有效提高体系对 污染物的降解和产电能力, 与微生物驯化等生物调控 手段相结合，可极大地扩展该技术的应用领域. 如表S2 所示，使用高活性光/电催化电极(阴极或阳极)的耦合 MFC已突破了传统微生物体系在适用水质方面的限 制，可用于难生化的工业废水或难降解污染物的处理, 并且在现阶段的研究中通常具有比PFC体系更优的产 电性能(PFC, $P_{\text {max }} \approx 0.01 \sim 708 \mathrm{~mW} \mathrm{~cm}^{-2}$, 表S1; MFC, $P_{\max } \approx 43.4 \sim 970 \mathrm{~mW} \mathrm{~cm}{ }^{-2}$, 表 $\mathrm{S} 2$ ), 技术优势显著.
研究表明，高活性催化电极在MFC体系中引人的 微生物-光/电催化的协同作用机制, 可显著提高污染物 的去除速率，并同时优化系统资源与能源的回收效率. 典型的光电催化阴极耦合MFC体系作用原理如图4(a) 所示. 与传统的MFC相比, 这类MFC耦合体系扩展了传 统电极的作用方式，使得污染物能够在阴极同时发生 氧化还原反应，从而在阴极室进一步强化降解. Zhang 和 $\mathrm{Liu}^{[97]}$ 将催化改性的颗粒活性炭电极 $\left(\mathrm{MnO}_{2} / \mathrm{TiO}_{2} / \mathrm{g}\right.$ $\mathrm{C}_{3} \mathrm{~N}_{4} @ \mathrm{GAC}$ )用于MFC阴极(图5(a)), 扩展了二维电极的 比表面积，使该耦合体系能够高效处理实际工业有机 酸废水(COD、氨氮、硝氮去除率均高于 $98 \%)$, 并回收 $1176.47 \mathrm{~mW} \mathrm{~m}^{-3}$ 的电能, 最大运行能耗仅为 334.66 $\mathrm{kW} \mathrm{h} \mathrm{kg}_{\mathrm{COD}}{ }^{-1}$. $\mathrm{Li}^{\text {等人 }}{ }^{[98]}$ 通过电极的优化, 将光-电催化 与膜分离技术原位耦合，构建的MFC-MBR体系; 在可 见光照射下，体系产电 $\left(942 \mathrm{~mW} \mathrm{~m}^{-3}\right)$ 和盐酸四环素 (98\%)去除速率均得到了明显的提升. Feng等人 ${ }^{[99]}$ 则是 对MFC的阳极进行光-电催化改性, 构建了负载 $\alpha-\mathrm{Fe}_{2} \mathrm{O}_{3}$ 的3D不锈钢电极; 研究表明, 光催化阳极与产电微生物 之间存在协同作用(图4(b))，光照下该耦合体系的产电 性能提高了 1.8 倍.

与单室MFC相比，双室MFC可分别控制阴极和阳 极的进水水质，在处理难生化废水中具有较大的优势. 例如, Wang等人 ${ }^{[100]}$ 将对微生物具有毒性作用的重金属 (含铜)废水控制在阴极进人，不与微生物直接接触，利 用生物电化学作用实现了有机物和重金属的同步去除. 然而, 传统双室MFC需要使用离子交换膜, 不仅增大了 体系内阻，还增加了运行成本(Nafion质子交换膜成本

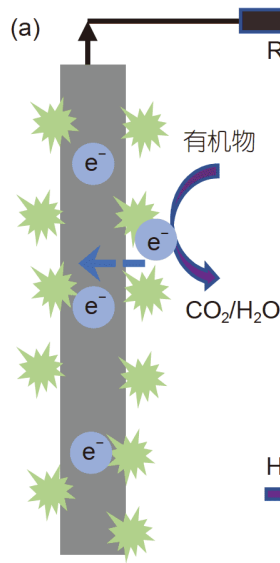

阳极

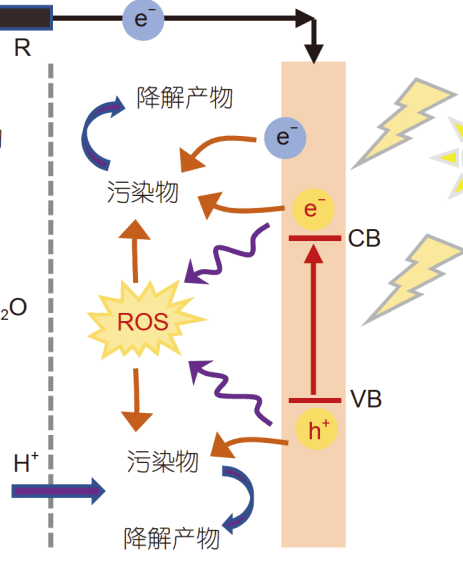

阴极

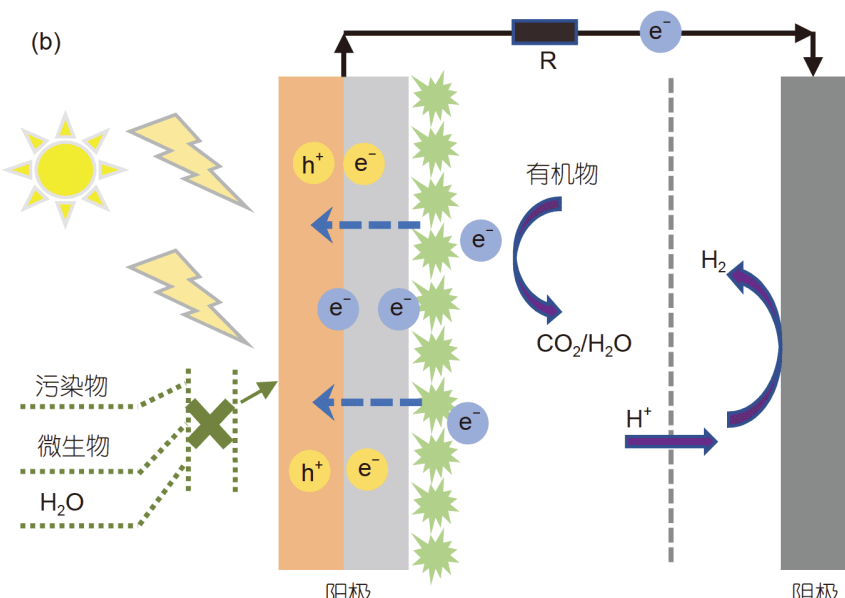

阳极

图 4 (网络版彩色)光电催化阴极耦合MFC体系(a)和光电催化阳极耦合MFC体系(b)原理示意图 ${ }^{[99]}$

Figure 4 (Color online) Schematic diagram of an integrated MFC system with photo-electro-catalytic cathode (a) and an integrated MFC system with photo-electro-catalytic anode $(b)^{[99]}$ 

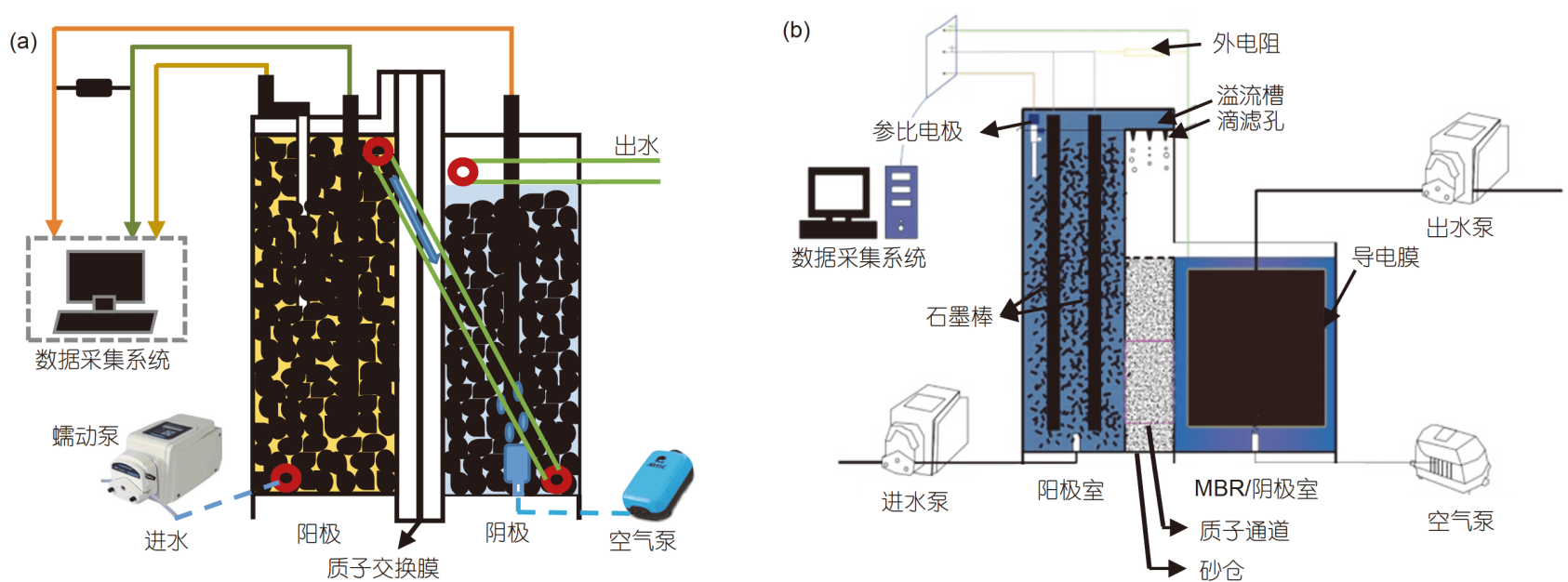

图 5 (网络版彩色) $\mathrm{MnO}_{2} / \mathrm{TiO}_{2} / \mathrm{g}_{-} \mathrm{C}_{3} \mathrm{~N}_{4} @ \mathrm{GAC}$ 颗粒催化电极微生物燃料电池体系(a) ${ }^{[07]}$ 以及碳基 $\mathrm{RGO} / \mathrm{PVDF} / \mathrm{MnO}_{2}$ 膜阴极生物电化学系统(b) ${ }^{[101]}$ Figure 5 (Color online) A microbial fuel cell reactor system with $\mathrm{MnO}_{2} / \mathrm{TiO}_{2} / \mathrm{g}-\mathrm{C}_{3} \mathrm{~N}_{4} @ \mathrm{GAC}$ catalytic electrode (a) ${ }^{[97]}$ and a bio-electrochemical system (BES) with carbon-based $\mathrm{RGO} / \mathrm{PVDF} / \mathrm{MnO}_{2}$ membrane cathode (b) ${ }^{[101]}$

高达2500 US $\left.\$ \mathrm{~m}^{-2[66]}\right)$. 为克服这一不足, Gao等人 ${ }^{[101]}$ 创新性地在 $\mathrm{RGO} / \mathrm{PVDF} / \mathrm{MnO}_{2}$ 催化导电膜耦合的MFC 中设置砂仓, 使用石英砂替代质子交换膜(PEM), 不仅 降低了体系的运行成本, 还将体系产电的最大功率密 度提高至 $228 \mathrm{~mW} \mathrm{~m}^{-3}$, 比使用PEM时高 1.5 倍, 体系内 阻也降低了 $185 \Omega$; 其中, 滴滤的设计使进人阴极室的 废水能够主动富氧, 减少阴极曝气的能量消耗(图5(b)).

\section{3 其他燃料电池组合工艺}

对于较成分复杂的难降解工业废水, 将电池型耦 合体系与其他电化学工艺进行组合, 可在多级系统中 逐步优化出水, 减少传统电化学工艺的能源消耗. 例 如， Liu等人 ${ }^{[102]}$ 将单光电极的PFC与PEC联用，利用 $\mathrm{PFC}$ 为 $\mathrm{PEC}$ 提供外加电压，同步去除有机污染物和产 氢；PEC-PFC组合工艺获得了比PEC高 1.5 倍的光电流 密度 $\left(0.3 \mathrm{~A} \mathrm{~m}^{-2}\right)$. 与之类似, 高效、低能耗的MFC-PEC 组合工艺已用于偶氮染料、抗生素、苯酚、苯胺等难 降解污染物的去除 ${ }^{[103 ~ 105]}$. Sui等人 ${ }^{[106]}$ 创新性地将PFC 单元与电脱盐单元相结合, 利用 $\mathrm{TiO}_{2} / \mathrm{Ti}$ 催化电极实现 了同步 $\mathrm{RhB}$ 降解 $\left(0.0505 \mathrm{~min}^{-1}\right)$ 、脱盐 $(58.25 \%, 36 \mathrm{~h})$ 和 产电 $\left(319.70 \mathrm{~mW} \mathrm{~m}^{-2}\right)$. 可见, 高效光催化电极耦合的 电池型耦合体系在废水资源化、能源化处理中还有多 种可能, 其在耦合机理和应用方面的创新有深人研究 的空间.

尽管在现阶段多级处理工艺更易实现出水水质的 优化, 但从长远来看, 工艺的简化和各单元的高效集成
是新型废水处理技术发展的趋势. 通过技术的优化和 改良减少预处理或多级体系的串并联，可极大地减少 实际废水处理中的基建费用和运行成本，对燃料电池 耦合废水处理技术走向实际应用具有重要的意义.

\section{3 总结与展望}

新型、高活性催化电极在PFC、MFC等电池型电 化学耦合体系中的应用促进了工业废水的资源化与能 源化处理. 这种绿色、节能、可持续的新型废水处理 技术有望替代传统生物法和物化法，得到更广泛的应 用. 然而, 燃料电池耦合催化污染控制水处理技术在工 业化应用中还存在着一些挑战: (1) 新型光/电催化电极 对多种作用方式的高效集成及其在低成本、节能化方 面的改良．具体包括：降低原料成本、简化制备方法; 通过组分和结构的优化原位耦合AOPs、膜分离或其 他多种作用机制; 利用自然光(可见光)代替紫外光激发 光电效应; 提高电极的稳定性和重复利用性等. (2) 燃 料电池催化耦合体系在废水资源化与能源化方面的创 新性应用. 主要是指通过电极性能和体系结构的优化 提高电能回收效率，或推动燃料电池耦合体系在交叉 学科领域中的应用，如在废水处理的同时实现脱盐、 产氢、重金属回收等. (3) 高活性催化电极的扩大化生 产及耦合体系的规模化应用. 主要包括: 电极扩大化生 产中的成本控制和催化活性、稳定性调控; 工艺流程 的简化及单元集成效率的提升，如减少曝气、减少外 加试剂的投人、减少预处理和多级体系的串并联等. 
1 Ministry of Ecology and Environment of the People's Republic of China. Annual Report of China’s Environmental Statistics·2015 (in Chinese). Beijing: China Environment Publishing Group, 2016 [中华人民共和国生态环境部. 中国环境统计年报2015. 北京: 中国环境出版社, 2016]

2 Yang H Y, Qi G X, Wang J H, et al. Research progress on electrochemical treatment technologies for refractory pollutants in wastewater (in Chinese). Appl Chem Ind, 2020, 49: 681-686 [杨虹燕, 齐高相, 王建辉, 等. 废水中难降解污染物电化学处理技术研究进展. 应用化工, 2020, 49: $681-686]$

3 Liu Y, Wu Z Y, Peng P, et al. A pilot-scale three-dimensional electrochemical reactor combined with anaerobic-anoxic-oxic system for advanced treatment of coking wastewater. J Environ Manage, 2020, 258: 110021

4 Ke S. Applications of membrane separation technology in wastewater treatment (in Chinese). Shanghai Environ Sci, 2020, 39: 66-68 [柯胜. 膜分 离技术在废水处理中的应用. 上海环境科学, 2020, 39: 66-68]

5 Antony A, Low J H, Gray S, et al. Scale formation and control in high pressure membrane water treatment systems: A review. J Membr Sci, 2011, 383: $1-16$

6 Li F J, Su H, Li X L, et al. Review on application of advanced oxidation technology in refractory industrial wastewater treatment (in Chinese). Environ Prot Technol, 2017, 23: 55-64 [李风娟, 宿辉, 李小龙, 等. 高级氧化技术在难降解工业废水处理中的应用研究进展. 环保科技, 2017, 23: 55-64]

7 Feng Y, Yang L, Liu J, et al. Electrochemical technologies for wastewater treatment and resource reclamation. Environ Sci-Water Res Technol, 2016, 2: 800-831

8 Hu C Z, Liu H J, Qu J H. Research progress of electrochemical technologies for water treatment (in Chinese). Chin J Environ Eng, 2018, 12: 677696 [胡承志, 刘会娟, 曲久辉. 电化学水处理技术研究进展. 环境工程学报, 2018, 12: 677-696]

9 Ding J, Wei L, Huang H, et al. Tertiary treatment of landfill leachate by an integrated electro-oxidation/electro-coagulation/electro-reduction process: Performance and mechanism. J Hazard Mater, 2018, 351: 90-97

10 Baldisserri C, Ortelli S, Blosi M, et al. Pilot-plant study for the photocatalytic/electrochemical degradation of Rhodamine B. J Environ Chem Eng, 2018, 6: 1794-1804

11 Feng Y J, Cui Y H, Sun L X, et al. Development of electro-chemical technology and high efficiency catalytic electrode for wastewater treatment (in Chinese). J Harbin Inst Technol, 2004, 36: 450-455 [冯玉杰, 崔玉虹, 孙丽欣, 等. 电化学废水处理技术及高效电催化电极的研究与进展. 哈尔滨工业大学学报, 2004, 36: 450-455]

12 Fujishima A, Honda K. Electrochemical photolysis of water at a semiconductor electrode. Nature, 1972, 238: 37-38

13 Liang S, Lin H, Yan X, et al. Electro-oxidation of tetracycline by a Magnéli phase $\mathrm{Ti}_{4} \mathrm{O}_{7}$ porous anode: Kinetics, products, and toxicity. Chem Eng J, 2017, 332: 628-636

14 Cheng F, Su Y, Liang J, et al. $\mathrm{MnO}_{2}$-based nanostructures as catalysts for electrochemical oxygen reduction in alkaline media. Chem Mater, 2010, 22: 898-905

15 Reddy C V, Reddy K R, Shetti N P, et al. Hetero-nanostructured metal oxide-based hybrid photocatalysts for enhanced photoelectrochemical water splitting-A review. Int J Hydrog Energy, 2020, 45: 18331

16 Jin J, Yu J, Guo D, et al. A hierarchical Z-scheme CdS- $\mathrm{WO}_{3}$ photocatalyst with enhanced $\mathrm{CO}_{2}$ reduction activity. Small, 2015, 11: 5262-5271

17 Tao X, Pan P, Huang T, et al. In-situ construction of $\mathrm{Co}(\mathrm{OH})_{2}$ nanoparticles decorated urchin-like WO 3 for highly efficient degradation of sulfachloropyridazine via peroxymonosulfate activation: Intermediates and DFT calculation. Chem Eng J, 2020, doi: 10.1016/j.cej.2020.125186

18 Guan J, Li C, Zhao J, et al. FeOOH-enhanced bifunctionality in $\mathrm{Ni}_{3} \mathrm{~N}$ nanotube arrays for water splitting. Appl Catal B-Environ, 2020, 269: 8

19 Zhu $\mathrm{H}$, Zhang S, Huang Y X, et al. Monodisperse $\mathrm{M}_{x} \mathrm{Fe}_{3-x} \mathrm{O}_{4}(\mathrm{M}=\mathrm{Fe}, \mathrm{Cu}, \mathrm{Co}, \mathrm{Mn})$ nanoparticles and their electrocatalysis for oxygen reduction reaction. Nano Lett, 2013, 13: 2947-2951

20 Kim T W, Choi K S. Nanoporous $\mathrm{BiVO}_{4}$ photoanodes with dual-layer oxygen evolution catalysts for solar water splitting. Science, 2014, 343: 990-994

21 Thomas A, Fischer A, Goettmann F, et al. Graphitic carbon nitride materials: Variation of structure and morphology and their use as metal-free catalysts. J Mater Chem, 2008, 18: 4893-4908

22 Ong W, Tan L, Ng Y, et al. Graphitic carbon nitride $\left(\mathrm{g}-\mathrm{C}_{3} \mathrm{~N}_{4}\right)$-based photocatalysts for artificial photosynthesis and environmental remediation: Are we a step closer to achieving sustainability? Chem Rev, 2016, 116: 7159-7329

$23 \mathrm{Xu} \mathrm{Y,} \mathrm{Kraft} \mathrm{M,} \mathrm{Xu} \mathrm{R.} \mathrm{Metal-free} \mathrm{carbonaceous} \mathrm{electrocatalysts} \mathrm{and} \mathrm{photocatalysts} \mathrm{for} \mathrm{water} \mathrm{splitting.} \mathrm{Chem} \mathrm{Soc} \mathrm{Rev,} \mathrm{2016,} \mathrm{45:} \mathrm{3039-3052}$

24 Zhang Y, Liu L, Van der Bruggen B, et al. Nanocarbon based composite electrodes and their application in microbial fuel cells. J Mater Chem A, 2017, 5: 12673-12698

25 Wang Z, Lai C, Qin L, et al. ZIF-8-modified $\mathrm{MnFe}_{2} \mathrm{O}_{4}$ with high crystallinity and superior photo-Fenton catalytic activity by Zn-O-Fe structure for 
TC degradation. Chem Eng J, 2020, 392: 124851

26 Furukawa H, Cordova K E, O'Keeffe M, et al. The chemistry and applications of metal-organic frameworks. Science, 2013, $341: 974$

27 Lee J Y, Farha O K, Roberts J, et al. Metal-organic framework materials as catalysts. Chem Soc Rev, 2009, 38: 1450-1459

28 Gao G, O’Mullane A P, Du A. 2D MXenes: A new family of promising catalysts for the hydrogen evolution reaction. ACS Catal, 2017, 7: 494500

29 Moniz S J A, Shevlin S A, Martin D J, et al. Visible-light driven heterojunction photocatalysts for water splitting-A critical review. Energy Environ Sci, 2015, 8: 731-759

30 Ye M, Zhao Z, Hu Z, et al. 0D/2D heterojunctions of vanadate quantum dots/graphitic carbon nitride nanosheets for enhanced visible-light-driven photocatalysis. Angew Chem Int Edit, 2017, 56: 8407-8411

31 Chen Y, Ji S, Chen C, et al. Single-atom catalysts: Synthetic strategies and electrochemical applications. Joule, 2018, 2: 1242-1264

32 Sivanantham A, Ganesan P, Shanmugam S. Hierarchical $\mathrm{NiCo}_{2} \mathrm{~S}_{4}$ nanowire arrays supported on Ni foam: An efficient and durable bifunctional electrocatalyst for oxygen and hydrogen evolution reactions. Adv Funct Mater, 2016, 26: 4661-4672

33 Ren $\mathrm{Y}, \mathrm{Xu} \mathrm{Q}$, Zheng $\mathrm{X}$, et al. Building of peculiar heterostructure of Ag/two-dimensional fullerene shell- $\mathrm{WO}_{3-x}$ for enhanced photoelectrochemical performance. Appl Catal B-Environ, 2018, 231: 381-390

$34 \mathrm{Ke} \mathrm{J}$, Liu J, Sun H, et al. Facile assembly of $\mathrm{Bi}_{2} \mathrm{O}_{3} / \mathrm{Bi}_{2} \mathrm{~S}_{3} / \mathrm{MoS}_{2}$ n-p heterojunction with layered n- $\mathrm{Bi}_{2} \mathrm{O}_{3}$ and p-MoS for enhanced photocatalytic water oxidation and pollutant degradation. Appl Catal B-Environ, 2017, 200: 47-55

35 Wang D, Chen Y. Critical review of the influences of nanoparticles on biological wastewater treatment and sludge digestion. Crit Rev Biotechnol, 2016, 36: 816-828

36 Chen T Y, Vedhanarayanan B, Lin S Y, et al. Electrodeposited NiSe on a forest of carbon nanotubes as a free-standing electrode for hybrid supercapacitors and overall water splitting. J Colloid Interface Sci, 2020, 574: 300-311

37 Sopha H, Hromadko L, Motola M, et al. Fabrication of $\mathrm{TiO}_{2}$ nanotubes on Ti spheres using bipolar electrochemistry. Electrochem Commun, 2020, 111: 106669

$38 \mathrm{Li} \mathrm{C} \mathrm{W,} \mathrm{Kanan} \mathrm{M} \mathrm{W.} \mathrm{CO}_{2}$ reduction at low overpotential on $\mathrm{Cu}$ electrodes resulting from the reduction of thick $\mathrm{Cu}_{2} \mathrm{O}$ films. J Am Chem Soc, 2012, 134: 7231-7234

39 Yu T, Liu L, Yang F. Heterojunction between anodic $\mathrm{TiO}_{2} / \mathrm{g}-\mathrm{C}_{3} \mathrm{~N}_{4}$ and cathodic $\mathrm{WO}_{3} / \mathrm{W}$ nano-catalysts for coupled pollutant removal in a selfbiased system. Chin J Catal, 2017, 38: 270-277

40 Zhao H, Li Z, Deng J, et al. Amorphous $\mathrm{MoS}_{2}$ nanosheets on $\mathrm{MoO}_{2}$ films/Mo foil as free-standing electrode for synergetic electrocatalytic hydrogen evolution reaction. Int J Hydrog Energy, 2020, 45: 17422-17433

41 Xia L, Bai J, Li J, et al. A highly efficient $\mathrm{BiVO}_{4} / \mathrm{WO}_{3} / \mathrm{W}$ heterojunction photoanode for visible-light responsive dual photoelectrode photocatalytic fuel cell. Appl Catal B-Environ, 2016, 183: 224-230

42 Bahmani F, Kazemi S H, Wu Y, et al. $\mathrm{CuMnO}_{2}$-reduced graphene oxide nanocomposite as a free-standing electrode for high-performance supercapacitors. Chem Eng J, 2019, 375: 121966

$43 \mathrm{He}$ J, Sun H, Dai J, et al. In situ growth of nanoflake and nanoflower-like Ni hydrated hydroxide on the surface of Ni foam as a free-standing electrode for high-performance phosphate detection. J Hazard Mater, 2020, 392: 122313

44 Zhang Y, Liu L, Van der Bruggen B, et al. A free-standing 3D nano-composite photo-electrode- $\mathrm{Ag} / \mathrm{ZnO}$ nanorods arrays on Ni foam effectively degrade berberine. Chem Eng J, 2019, 373: 179-191

45 Yang L, Li H, Yu Y, et al. Assembled 3D MOF on 2D nanosheets for self-boosting catalytic synthesis of N-doped carbon nanotube encapsulated metallic Co electrocatalysts for overall water splitting. Appl Catal B-Environ, 2020, 271: 118939

46 Aminullah, Kasi A K, Najma B, et al. Fabrication of piezoelectric nanogenerator using 3D-ZnO nanosheets and optimization of charge storage system. Mater Res Bull, 2020, 123: 110711

47 Jia Q, Gao Y, Li Y, et al. Cobalt nanoparticles embedded in N-doped carbon on carbon cloth as free-standing electrodes for electrochemicallyassisted catalytic oxidation of phenol and overall water splitting. Carbon, 2019, 155: 287-297

48 Guo X, Zhu Y, Han W, et al. Nitrogen-doped graphene quantum dots decorated graphite foam as ultra-high active free-standing electrode for electrochemical hydrogen evolution and phenol degradation. Chem Eng Sci, 2019, 194: 54-57

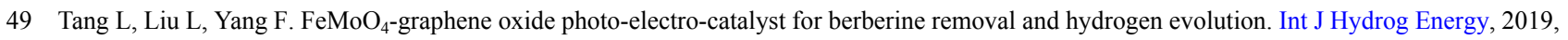
44: $19755-19761$

50 Sun J, Liu L, Yang F. A $\mathrm{WO}_{3} / \mathrm{PPy} / \mathrm{ACF}$ modified electrode in electrochemical system for simultaneous removal of heavy metal ion $\mathrm{Cu}^{2+}$ and organic acid. J Hazard Mater, 2020, 394: 122534

51 Li Q, Wang J, Liu C, et al. Controlled design of a robust hierarchically porous and hollow carbon fiber textile for high-performance freestanding electrodes. Adv Sci, 2019, 6: 1900762

52 Rao C R K, Trivedi D C. A novel one-pot synthesis of free standing Pd-PPy films: Observation of enhanced catalytic effect by Pd-PPy layers. 
Catal Commun, 2006, 7: 662-668

53 Khumngern S, Choosang J, Thavarungkul P, et al. Flow injection enzyme-free amperometric uric acid sensor consisting of ordered mesoporous carbon decorated with 3D Pd-Pt alloy nanodendrite modified screen-printed carbon electrode. Microchem J, 2020, 157: 104923

54 Arenas L F, Ponce de León C, Walsh F C. 3D-printed porous electrodes for advanced electrochemical flow reactors: A Ni/stainless steel electrode and its mass transport characteristics. Electrochem Commun, 2017, 77: 133-137

55 Vaněčková E, Bouša M, Nováková L Š, et al. 3D printed polylactic acid/carbon black electrodes with nearly ideal electrochemical behaviour. J Electroanal Chem, 2020, 857: 113745

56 Gusmão R, Browne M P, Sofer Z, et al. The capacitance and electron transfer of 3D-printed graphene electrodes are dramatically influenced by the type of solvent used for pre-treatment. Electrochem Commun, 2019, 102: 83-88

57 Iffelsberger C, $\mathrm{Ng} \mathrm{S}$, Pumera M. Catalyst coating of 3D printed structures via electrochemical deposition: Case of the transition metal chalcogenide $\mathrm{MoS}_{x}$ for hydrogen evolution reaction. Appl Mater Today, 2020, 20: 100654

58 Gusmão R, Sofer Z, Marvan P, et al. $\mathrm{MoS}_{2}$ versatile spray-coating of 3D electrodes for the hydrogen evolution reaction. Nanoscale, 2019, 11: 9888-9895

59 Nareejun W, Ponchio C. Novel photoelectrocatalytic/solar cell improvement for organic dye degradation based on simple dip coating $\mathrm{WO}_{3} / \mathrm{BiVO}_{4}$ photoanode electrode. Sol Energy Mater Sol Cells, 2020, 212: 110556

60 Di Y, Jia S, Li N, et al. Electrocatalytic films of PEDOT incorporating transition metal phosphides as efficient counter electrodes for dye sensitized solar cells. Sol Energy, 2019, 189: 8-14

61 Yang X, Yang Q, Xu J, et al. Bimetallic PtPd nanoparticles on Nafion-graphene film as catalyst for ethanol electro-oxidation. J Mater Chem, 2012, 22: 8057

62 Cai X, Ogorevc B I, Tavcar G, et al. Indium-tin oxide film electrode as catalytic amperometric sensor for hydrogen peroxide. Analyst, 1995, 120: $2579-2583$

63 Patil S A, Hussain S, Shrestha N K, et al. Facile synthesis of cobalt-nickel sulfide thin film as a promising counter electrode for triiodide reduction in dye-sensitized solar cells. Energy, 2020, 202: 117730

64 Nahyoon N A, Liu L, Rabe K, et al. Significant photocatalytic degradation and electricity generation in the photocatalytic fuel cell (PFC) using novel anodic nanocomposite of $\mathrm{Fe}$, graphene oxide, and titanium phosphate. Electrochim Acta, 2018, 271: 41-48

65 Alpatova A, Meshref M, McPhedran K N, et al. Composite polyvinylidene fluoride (PVDF) membrane impregnated with $\mathrm{Fe}_{2} \mathrm{O}_{3}$ nanoparticles and multiwalled carbon nanotubes for catalytic degradation of organic contaminants. J Membr Sci, 2015, 490: 227-235

66 Yu T, Liu L, Yang Q, et al. Catalytic and filterable polyester-filter membrane electrode with a high performance carbon foam-Fe-Co catalyst improved electricity generation and waste-water treatment in MBR-MFC. RSC Adv, 2015, 5: 48946-48953

67 Li Y, Liu L, Yang F. High flux carbon fiber cloth membrane with thin catalyst coating integrates bio-electricity generation in wastewater treatment. J Membr Sci, 2016, 505: 130-137

68 Allioux F M, David O, Merenda A, et al. Catalytic nickel and nickel-copper alloy hollow-fiber membranes for the remediation of organic pollutants by electrocatalysis. J Mater Chem A, 2018, 6: 6904-6915

69 Bi Q, Gao Y, Dang C, et al. Study on the photoelectrocatalytic performance of a $\mathrm{WO}_{3}$ thin film electrode by constructing a $\mathrm{BiOI} / \mathrm{WO}_{3}$ heterojunction. CrystEngComm, 2019, 21: 6744-6757

70 Blanco E, González-Leal J M, Ramírez-del Solar M. Photocatalytic $\mathrm{TiO}_{2}$ sol-gel thin films: Optical and morphological characterization. Sol Energy, 2015, 122: 11-23

71 Ganesh V, Latha Maheswari D, Berchmans S. Electrochemical behaviour of metal hexacyanoferrate converted to metal hydroxide films immobilized on indium tin oxide electrodes - Catalytic ability towards alcohol oxidation in alkaline medium. Electrochim Acta, 2011, 56: 11971207

72 Yang S B, Tsai Y C, Wu M S. Honeycomb-like copper/cuprous oxide with supported nickel hydroxide layer as an electrode material for electrochemical oxidation of urea. J Alloys Compd, 2020, 836: 155533

73 Munawar K, Mansoor M A, Olmstead M M, et al. Fabrication of Ag-ZnO composite thin films for plasmonic enhanced water splitting. Mater Chem Phys, 2020, 36: 123220

74 Alsultan M, Choi J, Jalili R, et al. Synergistic amplification of (photo)catalytic oxygen and hydrogen generation from water by thin-film polypyrrole composites. Mol Catal, 2020, 490: 110955

$75 \mathrm{He} \mathrm{C}, \mathrm{Li} \mathrm{X} \mathrm{Z}$, Graham N, et al. Preparation of $\mathrm{TiO}_{2} / \mathrm{ITO}$ and $\mathrm{TiO}_{2} / \mathrm{Ti}$ photoelectrodes by magnetron sputtering for photocatalytic application. Appl Catal A-Gen, 2006, 305: 54-63

$76 \mathrm{Xu} \mathrm{S}$, Cheng N, Yin H, et al. Electrospray preparation of $\mathrm{CuInS}_{2}$ films as efficient counter electrode for dye-sensitized solar cells. Chem Eng J, 2020, 397: 125463

77 Bi Q, Gao Y, Wang Z, et al. Preparation of a direct Z-scheme thin-film electrode based on CdS $\mathrm{QD}^{\text {sensitized } \mathrm{BiOI} / \mathrm{WO}} \mathrm{O}_{3}$ and its 
photoelectrocatalytic performance. Colloid Surfs A-Physicochem Eng Asp, 2020, 599: 124849

$78 \mathrm{Su}$ Y, Liu G, Zeng C, et al. Carbon quantum dots-decorated $\mathrm{TiO}_{2} / \mathrm{g}-\mathrm{C}_{3} \mathrm{~N}_{4}$ film electrode as a photoanode with improved photoelectrocatalytic performance for 1,4-dioxane degradation. Chemosphere, 2020, 251: 126381

$79 \mathrm{Yu} \mathrm{T}$, Liu L, Li L, et al. A self-biased fuel cell with $\mathrm{TiO}_{2} / \mathrm{g}-\mathrm{C}_{3} \mathrm{~N}_{4}$ anode catalyzed alkaline pollutant degradation with light and without lightWhat is the degradation mechanism? Electrochim Acta, 2016, 210: 122-129

80 Backhurst J R, Coulson J M, Goodridge F, et al. A preliminary investigation of fluidized bed electrodes. J Electrochem Soc, 1969, 116: 1600

81 Zhang Y, Chen Z, Wu P, et al. Three-dimensional heterogeneous electro-Fenton system with a novel catalytic particle electrode for Bisphenol A removal. J Hazard Mater, 2020, 393: 120448

82 Hou B, Han H, Jia S, et al. Three-dimensional heterogeneous electro-Fenton oxidation of biologically pretreated coal gasification wastewater using sludge derived carbon as catalytic particle electrodes and catalyst. J Taiwan Instit Chem Eng, 2016, 60: 352-360

83 Ye W, Zhang W, Hu X, et al. Efficient electrochemical-catalytic reduction of nitrate using $\mathrm{Co} / \mathrm{AC}_{0.9}-\mathrm{AB}_{0.1}$ particle electrode. Sci Total Environ, 2020, 732: 139245

84 Wang Z, Qi J, Feng Y, et al. Preparation of catalytic particle electrodes from steel slag and its performance in a three-dimensional electrochemical oxidation system. J Industr Eng Chem, 2014, 20: 3672-3677

85 Zhang Y, Zhang D, Zhou L, et al. Polypyrrole/reduced graphene oxide aerogel particle electrodes for high-efficiency electro-catalytic synergistic removal of $\mathrm{Cr}(\mathrm{VI})$ and bisphenol A. Chem Eng J, 2018, 336: 690-700

86 Zeng Q, Lyu L, Gao Y, et al. A self-sustaining monolithic photoelectrocatalytic/photovoltaic system based on a $\mathrm{WO}_{3} / \mathrm{BiVO}_{4}$ photoanode and $\mathrm{Si}$ PVC for efficiently producing clean energy from refractory organics degradation. Appl Catal B-Environ, 2018, 238: 309-317

87 Khalik W F, Ho L N, Ong S A, et al. Optimization of degradation of reactive black 5 (RB5) and electricity generation in solar photocatalytic fuel cell system. Chemosphere, 2017, 184: 112-119

88 Li M, Liu Y, Dong L, et al. Recent advances on photocatalytic fuel cell for environmental applications-The marriage of photocatalysis and fuel cells. Sci Total Environ, 2019, 668: 966-978

89 Rabé K, Liu L, Nahyoon N A, et al. Enhanced rhodamine B and coking wastewater degradation and simultaneous electricity generation via anodic g- $\mathrm{C}_{3} \mathrm{~N}_{4} / \mathrm{Fe}^{0}(1 \%) / \mathrm{TiO}_{2}$ and cathodic $\mathrm{WO}_{3}$ in photocatalytic fuel cell system under visible light irradiation. Electrochim Acta, 2019, 298: 430-439

90 Wang B, Zhang H, Lu X Y, et al. Solar photocatalytic fuel cell using $\mathrm{CdS}_{-} \mathrm{TiO}_{2}$ photoanode and air-breathing cathode for wastewater treatment and simultaneous electricity production. Chem Eng J, 2014, 253: 174-182

$91 \mathrm{Yu}$ T, Wu W W, Liu L, et al. Novel ternary p-ZnIn $\mathrm{S}_{4} / \mathrm{rGO} / \mathrm{n}-\mathrm{g}-\mathrm{C}_{3} \mathrm{~N}_{4}$ Z-scheme nanocatalyst with enhanced antibiotic degradation in a dark selfbiased fuel cell. Ceram Int, 2020, 46: 9567-9574

92 Zhao K, Zeng Q, Bai J, et al. Enhanced organic pollutants degradation and electricity production simultaneously via strengthening the radicals reaction in a novel Fenton-photocatalytic fuel cell system. Water Res, 2017, 108: 293-300

93 Zhang Y, Chen Q, Liu L, et al. Activation of peroxymonosulfate and recycled effluent filtration over cathode membrane $\mathrm{CNFs}_{-} \mathrm{CoFe} \mathrm{O}_{4} / \mathrm{PVDF}$ in a photocatalytic fuel cell for water pollution control. Chem Eng J, 2020, 399: 125731

94 Zhang Y, Liu L, Chen Q, et al. Electricity generating \& high efficiency advanced oxidation process including peroxymonosulfate activation in photocatalytic fuel cell. Chem Eng J, 2019, 378: 122148

95 Li N, Tang S, Rao Y, et al. Improved dye removal and simultaneous electricity production in a photocatalytic fuel cell coupling with persulfate activation. Electrochim Acta, 2018, 270: 330-338

96 Qian D D. A review of microbial fuel cells (in Chinese). Energy Environ Prot, 2014, 28: 4-7 [钱丹丹. 微生物燃料电池的研究综述. 能源环境 保护, 2014, 28: 4-7]

97 Zhang Q, Liu L. A microbial fuel cell system with manganese dioxide/titanium dioxide/graphitic carbon nitride coated granular activated carbon cathode successfully treated organic acids industrial wastewater with residual nitric acid. Bioresour Technol, 2020, 304: 122992

$98 \mathrm{Li} \mathrm{Y}$, Sun J, Liu L, et al. A composite cathode membrane with $\mathrm{CoFe}_{2} \mathrm{O}_{4}-\mathrm{rGO} / \mathrm{PVDF}$ on carbon fiber cloth: Synthesis and performance in a photocatalysis-assisted MFC-MBR system. Environ Sci-Nano, 2017, 4: 335-345

99 Feng H, Tang C, Wang Q, et al. A novel photoactive and three-dimensional stainless steel anode dramatically enhances the current density of bioelectrochemical systems. Chemosphere, 2018, 196: 476-481

100 Wang H, Wang H, Gao C, et al. Enhanced removal of copper by electroflocculation and electroreduction in a novel bioelectrochemical system assisted microelectrolysis. Bioresour Technol, 2020, 297: 122507

101 Gao C, Liu L, Yu T, et al. Development of a novel carbon-based conductive membrane with in-situ formed $\mathrm{MnO}_{2}$ catalyst for wastewater treatment in bio-electrochemical system (BES). J Membr Sci, 2018, 549: 533-542

102 Liu X H, Du F, Chen Q Y, et al. An effective self-driven PFC-PEC hybrid system for hydrogen generation from organic substance. Electrochim Acta, 2017, 245: 379-385

103 Long X, Pan Q, Wang C, et al. Microbial fuel cell-photoelectrocatalytic cell combined system for the removal of azo dye wastewater. Bioresour 
Technol, 2017, 244: 182-191

104 Zhang M, Wang Y, Liang P, et al. Combined photoelectrocatalytic microbial fuel cell (PEC-MFC) degradation of refractory organic pollutants and in-situ electricity utilization. Chemosphere, 2019, 214: 669-678

105 Zeng L, Li X, Fan S, et al. Insight into $\mathrm{MoS}_{2}$ synthesis with biophotoelectrochemical engineering and applications in levofloxacin elimination. ACS Appl Energy Mater, 2018, 1: 3752-3762

106 Sui M, Dong Y, You H. Enhanced photocatalytic activity for the degradation of rhodamine B by integrating salinity gradient power into a photocatalytic fuel cell. RSC Adv, 2015, 5: 94184-94190

\section{补充材料}

表S1 光催化燃料电池体系处理工业废水/特征污染物研究进展

表S2 催化电极耦合微生物燃料电池处理工业废水/特征污染物研究进展

本文以上补充材料见网络版csb.scichina.com. 补充材料为作者提供的原始数据, 作者对其学术质量和内容负责. 


\title{
Progress on catalytic electrodes and fuel cell systems for industrial wastewater treatment
}

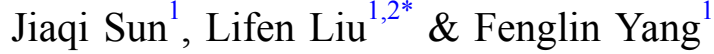 \\ ${ }^{1}$ Key Laboratory of Industrial Ecology and Environmental Engineering (Ministry of Education), School of Environmental Science and Technology, \\ Dalian University of Technology, Dalian 116024, China; \\ ${ }^{2}$ Key Laboratory of Industrial Ecology and Environmental Engineering (Ministry of Education), School of Ocean Science and Technology, Dalian Uni- \\ versity of Technology, Panjin 122441, China \\ * Corresponding author, E-mail: lifenliu@dlut.edu.cn
}

Industrial wastewater containing dyes, antibiotics, heavy metal ions and other refractory organic pollutants has complicated components and poor biodegradability. Comparing to traditional bio-treatment processes, electrochemical technologies have significant advantage in treating such kinds of wastewater due to the electrochemically generated reactive species. Modifying the electrodes with catalytic components can enhance pollutant removal capacity in electro-catalytic (EC) or photo-electro-catalytic (PEC) integrated systems, but high energy consumption of electricity still restricts their implement.

Self-biased fuel cells, including photocatalytic fuel cells (PFCs) and microbial fuel cells (MFCs), are more sustainable in industrial wastewater/pollutants treatment. Highly active catalytic electrodes are essential to promote pollutant removal and energy conservation. This article reviews the recent development of novel catalytic electrodes in preparation, optimization and sustainable application for industrial wastewater treatment. Technical advantages and optimization spaces of fuel-cell integrated systems (based on PFCs and MFCs) are introduced, and their challenges in large-scale application are pointed out.

Catalytic electrodes have broader application fields than powder-form catalysts due to the easy-recyclability and the synergy of catalysis and electrochemistry. An ideal catalytic electrode should be conductive, highly (photo-)electro-active, physically and chemically stable, easy to prepare and low-cost. By optimizing the preparation/loading of novel catalytic materials (heterojunctions, single-atom catalysts etc.), various catalytic electrodes, in forms of self-standing (metal-based, carbon-based and others), film/membrane and particles, etc., can be obtained with extraordinary (photo-)electro-catalytic activity. Innovative design of catalytic electrodes in structure and component may in-situ integrate multiple technologies such as (photo-)electro-catalysis, advanced oxidation processes (AOPs) and membrane filtration, etc., which provides more possibility for enhancing electrochemical systems. Novel catalytic electrode of low-cost and high efficiency is still desirable for further optimization of integrated electrochemical systems.

PFCs convert solar energy into electricity from the wastes (fuels). Various PFCs (single or dual photo-electrode(s)) have been developed for the degradation of dyes, antibiotics and other refractory pollutants. The electricity generation of novel PFC has been improved to $1 \mathrm{~V}$ (open circuit voltage) or more in some cases. Enhanced pollutant degradation and energy recovery by optimizing the function of electrode and structure of PFCs are still desirable for complex wastewater treatment.

By using exoelectrogens, highly-active catalytic electrodes (anode and/or cathode) can be applied in MFC integrated systems to promote the degradation of refractory pollutants. The synergy of bacteria and catalytic electrodes broadens the application of bio-processes in industrial wastewater treatment, and also benefits the energy recovery (electricity, hydrogen, heavy metals, etc.) of systems. Innovative designs of systems are expected to further reduce the operating costs from ion-exchange membrane, light irradiation and aeration.

Although pollutant removal and energy conservation of fuel cells can be further improved by integrating AOPs (Fenton process, sulfate or chlorine radical advanced oxidation, etc.) or combining other processes (EC, PEC, desalination, etc.), less chemical consumption and simpler system configuration/operation are the main trends of sustainable and cleaner production.

In the future, efforts need to be done for large-scale industrial wastewater treatment by fuel cell systems: (1) Develop novel catalytic electrodes of low-cost with enhanced performance (visible light response) and integrated functions (photoand/or electro-catalysis, filtration, AOPs, etc.). (2) Construct novel integrated fuel cell systems with highly active catalytic electrodes for multiple pollutant control and energy recovery. (3) Optimize large-scale preparation of catalytic electrodes, and simplify the operations of fuel cell systems, for energy-efficient and cost-effective treatment of real industrial wastewater, during long-term run.

catalytic electrode, electrochemical technologies, photocatalysis fuel cells, microbial fuel cells, industrial wastewater treatment 